\title{
PROPOSTA DE IMPLEMENTAÇÃO DA SALA DE LEITURA: VISANDO O DESENVOLVIMENTO PARA A FORMAÇÃO DE CIDADÃOS CRÍTICOS
}

\author{
Lysne Nôzenir de Lima ${ }^{1}$
}

\begin{abstract}
RESUMO: Este trabalho é um recorte de um Projeto de uma Sala de Leitura que tem como objetivo a implementação da sala de leitura em uma escola pública de ensino fundamental do Estado de Roraima localizada na periferia de Boa Vista, por meio de um professor capacitado que deverá realizar atividades de leitura com estratégia para desenvolver a criatividade, o pensamento lógico, incentivo, interesse e habito da leitura pelos educandos, em parceria com todos os professores, oportunizando assim o fortalecimento e integração no processo de ensino aprendizagem.
\end{abstract}

Palavras-chave: Sala de leitura; Educação; Práticas Pedagógicas.

ABSTRACT: This work is a clipping from the Reading Room Project which aims at the implementation of the reading room in a public school elementary school in the State of Roraima located on the outskirts of Boa Vista, through a trained teacher who shall attain activities reading with a strategy to develop creativity, logical thinking, encouragement, interest and educating the habit of reading, in partnership with all teachers, thus providing opportunities to strengthen and integrate the teaching-learning process.

Keywords: Reading Room; Education; Pedagogical Practices.

\section{INTRODUÇÃO}

Este trabalho foi resultado da elaboração de um projeto em que se buscou a implementação da sala de leitura de uma Escola Pública localizada na periferia de Boa Vista. No primeiro momento foram realizadas visitas na referida Escola para obter informações necessárias para a elaboração do projeto. Conhecer a sala de leitura, a escola e sua realidade através de observações e questionários semi-estruturados com a Gestão e 20\% do alunado.

Levantou-se o histórico da escola, atualmente a escola tem cerca de 620 alunos matriculados no Ensino Fundamental, a equipe Gestora é formada pelos seguintes profissionais: Gestor, Administradora Educacional que contam com o apoio do corpo técnico pedagógico e corpo docente, profissionais estes

\footnotetext{
${ }^{1}$ Mestrado em Educação pela Universidad de Alcalá (Espanha). Professora da Rede Pública de Ensino do Estado de Roraima. Contato: Iysne.lima@gmail.com
} 
habilitados e capacitados, que tem a missão de direcionar as ações educativas no sentido mais amplo, bem como gerenciar e compartilhar os saberes da instituição.

\section{UMA BREVE HISTÓRIA DA LEITURA}

Historicamente, a leitura se restringia apenas a algumas pessoas dentre elas, os filósofos e aristocratas. Na Idade Média, uma minoria era alfabetizada. As igrejas, os mosteiros e abadias uniram-se e formaram um único centro de pessoas letradas. Esses eram privilegiados em possuírem as únicas escolas e bibliotecas da época, preservavam e restauravam escritos antigos do legado Grego. Na época a educação formal entrou em conflito, ficando restrita a classe clerical que mantinha a escola somente para formação do clero. Dessa forma, à leitura passou a ter característica religiosa, a escrita, um símbolo sagrado, que tinha por finalidades respeitar e obedecer aos seus ensinamentos religiosos havendo a transmissão oral dos conhecimentos, onde a prática comum de leitura era a realização de recitações. Com isso as habilidades de leituras eram restritas a uma pequena parcela da sociedade, a qual fazia a leitura em voz alta de textos literários às diversas pessoas em praças ou logradouros públicos. Esses eram considerados autores ou profissionais da leitura.

Sobre a prática da leitura na Antiguidade Barbosa (1990, p.97-99) afirma que:

[...] apesar da representatividade das obras escritas, na antiguidade tratava-se ainda de civilizações pressas a uma cultura oral e auditiva, nas quais a cultura escrita representava um papel secundário [...]. Era inconcebível ler sem apelar para o som da escrita.

Com a evolução e as transformações sociais, houve necessidade de maior instrução. Nesse contexto, as escolas públicas começaram a ser implantadas. Então, a leitura tornou-se uma atividade importante para o homem, atendendo às varias finalidades, inserindo-o principalmente no mundo vasto de conhecimento. 
No Brasil, vivemos numa sociedade de classe, a que domina e a que obedece. A que domina procura através de diferentes meios e procedimentos cegarem as pessoas de modo a reproduzir o regime de privilégios ao longo da história. Assim, em uma sociedade competitiva e desigual, a educação não se torna um fator primordial.

Vivemos em um país capitalista, onde os programas governamentais não incentivam o desenvolvimento de conhecimentos e habilidades, músicas, danças que podem elevar o nível de instrumentalização da população como um todo e mesmo, quando sobra espaço para alguma atividade intelectual, e de forma fragmentada como um "soletrando da vida", que não valoriza a produção e nem a compreensão do mundo. Isso ocorre porque a escola reflete as contradições da sociedade excludente na qual vivemos.

Tal fato reafirma a necessidade de uma sala de leitura com um professor qualificado para atender as necessidades dos alunos.

Com esse profissional e com essa ação, a escola promove uma educação de qualidade, contribuindo significativamente para o desenvolvimento social, econômico, cultural da sociedade, pois possui um conjunto de princípios concretizados pela aplicação de proposta educacional que contem em seu bojo a formação de um cidadão critico e um processo educacional eficaz.

O referido projeto tem como público-alvo alunos do ensino fundamental das séries iniciais.

Visando melhorar o desempenho dos alunos no campo da comunicação e linguagem, o projeto Sala de Leitura se transformou em ação política educacional, atuando como parte integrante do currículo e tendo como base dois elementos fundamentais que o caracterizam: um espaço separado de atuação e um profissional específico para a realização de suas atividades o Professor Orientador de Sala de Leitura (POSL). Posteriormente, com a manutenção dessa ação, das atividades, a leitura tornou-se componente curricular obrigatório (MENDES, 2006). 
Os professores de sala de leitura possuem atribuições de realizar projetos voltados para leitura, além de organizar e conservar o espaço físico da sala.a

Desde o advento das salas de leitura no interior das escolas, o profissional responsável pelas atividades da sala de leitura passou a ter destaque no projeto, desde o início o êxito ou fracasso dos objetivos dessa ação política foram atribuídos à sua atuação nas escolas e de suas intervenções junto aos alunos (MENDES, 2006).

Esse profissional deve ser um professor titular, ou seja, efetivo, preferencialmente do próprio estabelecimento de ensino.

Cabe a ele ser o responsável por selecionar material para uso, conhecer o acervo, selecionar livros, administrar seções de leitura livre, orientar pesquisas, contar histórias, receber e guardar os livros e as fichas de leitura, organizar entrevistas com autores de literatura.

É de salutar relevância afirmar que o professor instituído para dinamizar a sala de leitura da Escola, deve propiciar um clima favorável á construção de conhecimento e de valores, dinamizando as ações de incentivo a leitura e por meio dela a busca de novos mundos imaginários que só a leitura proporciona, deverá prestar atendimento aos alunos dos turnos matutino e vespertino, por meio de um projeto pedagógico voltado para estimulo à leitura para todos os alunos, no sentido de desenvolver além do conhecimento teórico as operações cognitivas, através de uma abordagem educacional com foco no desenvolvimento da criatividade do indivíduo, através de ações específicas, que possam ser direcionadas a todos os alunos para o habito e busca do prazer de uma boa leitura, para tanto se deve buscar a adesão do grupo gestor, professores, alunos bem como familiares.

A educação é um direito estabelecido pela constituição, entre tanto tem sido o grande desafio enfrentado pelo país, que tem refletido como formar cidadãos críticos, consciente de seus deveres e direitos, enfim, o certo è que a rede pública de ensino não atingiu plenamente os objetivos propostos, ou seja, está à deriva, não recebe apoio suficiente para realizar suas atividades, 
apresenta dificuldade para capacitar seu corpo docente, falta de infra-estrutura, recursos humanos e materiais didáticos adequados.

Assim, com um olhar projetado para o futuro, a Escola vislumbra atingir as metas educacionais de aprendizagem estabelecidas em suas Diretrizes, considerando as dimensões individuais e grupais de aprendizagem. Neste sentido, levando em consideração o papel fundamental da leitura na vida dos educandos, esse trabalho apresenta proposta de implementação da sala de leitura.

Para tanto é de fundamental importância que a Escola disponibilize (01) um professor para atuar frente à sala de leitura, tal profissional terá a incumbência de melhorar a utilização do espaço, aumentar a freqüência e fazer com que o educando desperte o interesse pela leitura, no entanto a escola precisa implementar esse espaço.

Com esse profissional a Escola, está formando alunos críticos e participativos, além de estar buscando através da leitura uma forma eficaz de colaborar com o desenvolvimento cultural do Estado.

Para tanto reforçar-se que é necessário disponibilizar um professor especializado para desenvolver atividades de leitura junto aos alunos do ensino fundamental da Escola.

O qual entre outras funções deve:

- Desenvolver o habito da leitura;

- Promover nos alunos de ensino fundamental, momento de integração;

- Utilizar a leitura como ferramenta para incentivar a criatividade e a imaginação dos educandos;

- Desenvolver as habilidades lingüísticas: falar, escutar, ler e escrever;

- Estimular a aprendizagem aprender a conhecer aprender a ser, aprender a conviver, aprender a fazer;

- Propor situações de práticas leitoras com diferentes tipos e gêneros textuais; 
- Fazer com que o aluno vivencie emoções e fantasias, através da prática da leitura;

- Incentivar os educandos a participar dos concursos de leitura e redação promovidos pela escola e pelas entidades educacionais.

Esse trabalho metodologicamente é fruto de entrevista semi-estruturada com o Diretor da Escola, equipe pedagógica e alunos, assim como de pesquisa bibliográfica e observação "in loco".

Para realizar as atividades de estímulo à leitura, a escola Estadual disponibiliza uma sala de leitura com um professor comprometido com o processo de ensino/aprendizagem devendo inovar em ações que visem estimular os alunos que deverão realizar ações protagônicas frente às atividades que forem realizadas tais como: momento de leitura, oficinas literárias ou de elaboração de jornal e outros recursos de comunicação visual: exposições, palestras, mostras, excursões em pontos culturais seja do município ou do Estado, abarcando assim, um universo amplo de manifestações científico-culturais, além de ser um espaço propício para ensinar a FAZER que se refere a aplicação da realidade, mediante capacidades, habilidades e destreza. Manifesta-se mediante a ação, iniciativa, criatividade, concretização, e pragmatismo. A vivência dos alunos, sua cultura e valores estão presentes, através da fala, da escrita, da imagem ali construída.

\section{AÇÕES/ATIVIDADES QUE PODERÃO SER EXECUTADAS}

De acordo com Ezequiel Silva (2002, p. 21), não se forma leitor com uma ou duas cirandas e nem com uma ou duas sacolas de livros, se as condições sociais e escolares, subjacentes á leitura, não forem consideradas e transformadas. Em nossa intimidade, todos nós sabemos que, aos nos confrontamos com textos densos e inusitados ou até mesmo textos anteriormente lidos, estamos aprendendo a ler - isto vem demonstrar que $o$ ato de ler, se devidamente enraizado na vida do sujeito, não pode ser saciado nos limites fechados de acervos paternalmente doados ás escolas. 
Esta atividade da sala de leitura será conduzida pelo professor, que tem o objetivo de criar um momento mágico por meio da leitura, levando cada um dos alunos a vivenciarem os personagens encontrados nos livros, através de interpretações teatrais, direcionar a imaginação da criança, em mundos e situações inimaginável.

E através da leitura que o sujeito interage de forma integral no meio em que está inserido. Ler é fundamental para formar um sujeito livre e capaz de desempenhar seu verdadeiro papel e sua participação como cidadão na sociedade. Ela possibilita um conhecimento para a vida inteira, acontecendo de maneira formal e informal. Sobre isso, os PCN's (1997, p. 41) afirmam que:

\begin{abstract}
A leitura é um processo no qual o leitor realiza um trabalho ativo de construção de significados do texto, a partir de seus objetivos, de seu conhecimento sobre o assunto, sobre o autor, de tudo o que sabe a língua. Não se trata simplesmente de extrair informações da escrita decodificando - a letra por letra, palavra por palavra. Trata-se de uma atividade que implica, necessariamente antes da leitura propriamente dita.
\end{abstract}

Em relação a essa interação entre os conhecimentos prévios do sujeito leitor e os diversos textos escolares percebemos que de maneira processual a leitura está intimamente associada às atividades e exigências do mundo em constantes transformações. A criança, que, desde cedo, convive com atividades de leitura de diversos autores de textos facilitara o processo em que a criança relaciona os conteúdos dos textos escolares com o seu cotidiano, contribuindo para uma aprendizagem mais significativa.

A leitura formal é sistematizada na escola, na qual o professor desempenha um papel fundamental, disponibilizando recursos diversificados para que os alunos percebam a importância no seu cotidiano. Assim, a escola é o local em que aprendemos os elementos que a compõem e as diferentes estratégias de leitura, pois as mesmas são bastante amplas. Porém é importante ressaltar o verdadeiro significado dessa leitura e a importância que ela tem para a vida de cada um, sendo construídas nas experiências sociais dos sujeitos, porque acreditamos que aprender a ler começa bem antes de entrarmos na escola. Ou seja, a leitura informal que acontece na família, na rua 
com os amigos também influência a leitura formal. Esses são os conhecimentos prévios que o sujeito tem sobre a leitura.

Com essa visão o projeto de implementação da sala de leitura propõe desenvolver as seguintes ações:

\section{MOMENTO CULTURAL}

Neste momento o professor deve conduzir os alunos para a valorização da cultura local, através da leitura de contos e historias regionais do Estado de Roraima por meio basicamente de leituras, nessa atividade os alunos se sentirão à vontade para falar de sua rua, seu bairro e como vêem a cidade que vivem. Dessa forma, construir cidadãos conscientes de seu papel frente à sociedade.

\section{MOMENTO MÃOS À OBRA}

Serão convidados os alunos, grupo de salas de aula para buscar meios de conservação dos livros, neste momento os alunos darão sugestão para a conservação do acervo, bem como estarão á frente de campanhas e gincanas para a aquisição de novos livros. Com essa atividade procurar-se desenvolver no aluno o sentimento de responsabilidade social importante na construção de cidadão participativos.

\section{CONCURSO DE REDAÇÃO}

O concurso de redação visa estimular os alunos usuários da sala de leitura à participarem com mais interesse nas aulas, colocando em prática seu aprendizado conforme a série que se encontra.

\section{HORA DA LEITURA?}

Determinar sempre uma hora na semana ou no mês para que o aluno possa ser conduzido à sala da leitura para ler o livro que desejar, esse momento deve ser relaxante para o aluno tome o habito da leitura. 
A avaliação será feita de maneira contínua através da realização das atividades propostas, por meio de uma ficha que será preenchida pelo aluno depois de cada atividade.

\section{CONSIDERAÇÕES FINAIS}

No presente trabalho quando tratamos das práticas de leitura que podem contribuir com a formação do cidadão critico, verificamos que na referida escola os professores ainda utilizam em vários momentos, atividades de cópia que, apesar de serem importantes para o desenvolvimento de habilidades de escrita, não ensinam por si só os alunos a ler e escrever. Menos ainda, possibilitam o preparo do sujeito para ser um cidadão critico capaz de ler o escrito e a realidade ao seu redor, para posicionar-se e reposicionar-se na realidade social em que vive.

As atividades de leitura que ocorre nesse espaço escolar investigado, muitas vezes se dão de maneira descontextualizadas, sem levar em consideração que ler é um ato de interação entre o leitor e o texto. Assim, as crianças não demonstram interesse pelas atividades propostas, têm dificuldades para decifra e compreender o escrito. Isso, ao contrário de ajudar na formação de leitores proficientes e capazes de relacionar o conteúdo dos textos com a realidade em que vive os alunos, faz com que o ato de ler seja cansativo e penoso.

Juntamente a esses fatos cotidianos da escola os meios tecnológicos não estão contribuindo para o habito da leitura tendo sido pouco estimulado o que vêem fazendo com que o aprendizado seja cada vez mais lento, e as crianças cada vez mais estressadas com tantas informações e pouca clareza, então um espaço com profissional capacitado è sem duvida de grande importância e certamente trará resultados excelentes no que se refere ao aprendizado dos alunos, vez que comprovadamente a leitura estimula os dois lados do cérebro, que è responsável em: armazena e decodifica a informação, associação de outras informações, definição de estratégia para desenvolver a criatividade, além de desenvolver pensamento lógico e como aprender a aplicar esses conhecimentos em outras áreas e estimular a imaginação e a emoção. 
Desta forma não se conhece outro meio que se possa estimular tanto a capacidade de raciocínio como a leitura, diante disso vê-se a necessidades de fomentar ações continuadas de estimulo a esta atividade para os alunos.

\section{REFERÊNCIAS BIBLIOGRÁFICAS}

BRASIL. Ministério da Educação. Parâmetros Curriculares Nacionais (Área de Português). Brasília, DF: MEC/SEF, 1997.

MARTINS, Maria Helena. O que é leitura. São Paulo: Brasiliense, 2006.

MENDES, Monica de Fátima Valenzi. Sala de Leitura nas escolas da Rede Municipais de Ensino. São Paulo: Pontifícia Universidade Católica de São Paulo. Tese (Doutorado), 2006.

SILVA, Ezequiel Theodoro da. $\mathbf{O}$ ato de ler: fundamentos psicológicos para uma nova pedagogia da leitura. 9a ed. São Paulo: Cortez, 2002. 